Otto A. Baumhauer

Die sophistische Rhetorik 


\author{
Otto A. Baumhauer
}

\title{
Die sophistische Rhetorik
}

\section{Eine Theorie sprachlicher Kommunikation}

J. B. Metzlersche Verlagsbuchhandlung Stuttgart 
CIP-Kurztitelaufnahme der Deutschen Bibliothek Baumhauer, Otto A.:

Die sophistische Rhetorik : e. Theorie sprachl.

Kommunikation / Otto A. Baumhauer. - Stuttgart :

Metzler, 1986.

ISBN 978-3-476-00592-2

ISBN 978-3-476-00592-2

ISBN 978-3-476-03224-9 (eBook)

DOI 10.1007/978-3-476-03224-9

(C) 1986 Springer-Verlag GmbH Deutschland

Ursprünglich erschienen bei J. B. Metzlersche Verlagsbuchhandlung und Carl Ernst Poeschel Verlag GmbH in Stuttgart 1986 


\section{Vorwort}

Vor einigen Jahren wollte ich mit einem kurzen Aufsatz Kommunikationswissenschaftler auf die Probleme sprachlicher Kommunikation hinweisen, die von den sophistischen Rhetorikern behandelt worden sind gedacht als Beitrag zur Theoriediskussion. Der Aufsatz wurde nie geschrieben. Statt dessen entstanden Materialsammlungen und Darstellungen von Teilproblemen, teils fragmentarisch, teils ausufernd, jedenfalls für eine Publikation nicht geeignet.

Eine Erfahrung kam hinzu: In vielen Gesprächen entdeckte ich, daß die Vorstellungen von der sophistischen Rhetorik immer noch weitgehend von jenem Bild beherrscht werden, das Platon besonders in seinem Gorgias von ihr entworfen hat - Vorurteile gegen Sophisten und Rhetorik, die es fast unmöglich machen, Verständnis für die sophistische Rhetorik als ernst zu nehmende Theorie sprachlicher Kommunikation zu wecken.

So reifte allmählich der Plan, in der Auseinandersetzung mit Plato diese Vorurteile abzubauen und ein Bild der charakteristischen Grundzüge sophistischer Rhetorik zu entwerfen, das deren Aktualität und Bedeutung für die moderne Kommunikationswissenschaft erkennen läßt. Dieses Bild muß daher auch einsichtig machen, daß Reduktionen wie die auf eine Stillehre oder Wirkungsästhetik, auf eine Psychologie oder Argumentationstechnik der Rhetorik nicht gerecht werden.

Damit wendet sich das Buch aber nicht mehr nur an Kommunikationswissenschaftler, sondern an all jene, die sich für die Antike, für Rhetorik, die Kommunikationsprobleme unserer Zeit oder die Kommunikationsforschung interessieren - wendet sich nicht nur an den Fachmann, sondern auch an den Laien.

Neuburg a.d. Donau, im Juli $1985 \quad$ O. A. B. 


\section{Inhaltsverzeichnis}

Einleitung

Das Identitätsproblem der Kommunikationswissenschaft 9

Zur Quellenlage 12

Zum Vorgehen 19

\section{Erster Teil: Platon und die Rhetorik}

Platons Gorgias:

Die sophistische Rhetorik als Routine der Mengenkommunikation

Die Situation des Dialogs 22

Peri lógus 23

Die Definition der Rhetorik als peithûs demiurgós 27

Die lógoi 32

Der agón mit lógoi 37

Rhetorischer und platonisch-sokratischer élenchos 39

Das Ansehen des Redners 42

Das Bild des Redners in Platons Theaitetos 45

Zur Selbstdarstellung des sophistischen Redners 50

Der Redner und seine Macht 54

Der Redner und der dêmos 58

Die Rhetorik - eine Schmeichelei 61

Die Charakterisierung der Rhetorik als Fertigkeit und Routine 65

Die téchoe als wissenschaftsteoretisches Problem 74

Platons Phaidros:

Die dialektische Rhetorik als téchne der Seelenführung

Die Herausforderung des Isokrates 78

Die Rhetorik des Philosophen 79

Die téchne der lógoi 80

Gesprochener und geschriebener Text 81

Die téchne des Widersprechens und Widerlegens 83

Wahrheit und Wahrscheinlichkeit 84

Die dialektische téchne 85

Rhetorik als Seelenführung durch lógoi 87 
Der Aufbau des dialektischen lógos 89

Die dialektische téchne der lógoi 90

Zweiter Teil: Das Bild der sophistischen Rhetorik

Die historische Situation der Rhetorik

Die Anfänge der sophistischen Rhetorik 94

Die geistige Situation 99

Die politische Situation 106

Thukydides: Der Streit um die Rhetorik 112

Sophistisches Reden in des Aristophanes Wolken 122

Gegenstände der sophistischen Rhetorik

Inhalte sophistischer Rhetoriklehrbücher 130

Zur táxis 131

Die Idee des eikós 135

Antilogien und Sophismen 144

Thésis und tópoi 147

Êthos und páthos 157

Zur léxis 166

Dritter Teil: Theoretische Grundlagen der sophistischen Rhetorik

Zur Ontologie des Parmenides 182

Protagoras: Der Mensch - das Maß aller Dinge 183

Gorgias: Über das Nichtseiende oder die Natur 188

Schlußteil: Sophistische Rhetorik und Kommunikationswissenschaft

Sophistische Rhetorik als Theorie sprachlicher Kommunikation 200

Schlußbemerkungen 204

Anhang I: Glossar 207

Anhang II: Quellen 227

Literaturhinweise 232 